Amsterdam BHD working group and their affiliations, see the Acknowledgements section.

Correspondence: Pieter E. Postmus, Dept of Pulmonary Diseases, VU University Medical Center, PO Box 7057, 1007 MB Amsterdam, The Netherlands. E-mail: pe.postmus@vumc.nl

Received: Aug 012014 | Accepted: Nov 272014

Clinical trial: This study is registered at www.toetsingonline.nl with identifier number NL31417.029.10

Support statement: No funding was provided for this study.

Conflict of Interest: None declared.

Acknowledgements: The additional participating principal investigators of the Amsterdam BHD working group were Marianne A. Jonker (Dept of Epidemiology and Biostatistics, VU University Medical Center, Amsterdam the Netherlands), Arjan C. Houweling (Dept of Clinical Genetics, VU University Medical Center), Quinten Waisfisz (Dept of Clinical Genetics, VU University Medical Center), Johannes J.P. Gille (Dept of Clinical Genetics, VU University Medical Center), Erik Thunnissen (Dept of Pathology, VU University Medical Center), JanHein T.M. van Waesberghe (Dept of Radiology, VU University Medical Center) and Theo M. Starink (Dept of Dermatology, VU University Medical Center).

We are grateful to all included pneumothorax patients who participated in this study.

\title{
References
}

1 MacDuff A, Arnold A, Harvey J, et al. Management of spontaneous pneumothorax: British Thoracic Society Pleural Disease Guideline 2010. Thorax 2010; 65: Suppl 2, ii18-ii31.

2 Smit HJ, Wienk MA, Schreurs AJ, et al. Do bullae indicate a predisposition for recurrent pneumothorax? $\mathrm{Br} J$ Radiol 2000; 73: 356-359.

3 Johannesma PC, van Waesberghe JHTM, Reinhard R, et al. Chest CT for primary spontaneous pneumothorax (PSP): findings: Birt-Hogg-Dubé versus non-Birt-Hogg-Dubé patients. Am J Respir Crit Care Med 2014; 189: A6415.

4 Johannesma PC, Lammers JW, van Moorselaar RJ, et al. Spontaneous pneumothorax as the first manifestation of a hereditary condition with an increased renal cancer risk. Ned Tijdschr Geneeskd 2009; 153: A581.

5 Pierce CW, Hull PR, Lemire EG, et al. Birt-Hogg-Dubé syndrome: an inherited cause of spontaneous pneumothorax. CMAJ 2011; 183: E601-E603.

Verhaert LL. A young man with bilateral spontaneous pneumothorax. Case Rep Pulmonology 2011; 2011: 414165.

Hopkins TG, Maher ER, Reid E, et al. Recurrent pneumothorax. Lancet 2011; 377: 1624.

Johannesma PC, Thunnissen E, Postmus PE. Lung cysts as indicator for Birt-Hogg-Dubé syndrome. Lung 2014; 1952: 215-216.

9 Menko FH, van Steensel MA, Giraud S, et al. Birt-Hogg-Dubé syndrome: diagnosis and management. Lancet Oncol 2009; 10: 1199-1206.

10 Ren HZ, Zhu CC, Yang C, et al. Mutation analysis of the FLCN gene in Chinese patients with sporadic and familial isolated primary spontaneous pneumothorax. Clin Genet 2008; 74: 178-183.

11 Johannesma PC, Jonker MA, van der Wel MA, et al. Management of spontaneous pneumothorax in patients with or without Birt-Hogg-Dubé syndrome. Eur Respir J 2014; 44: Suppl. 58, 752.

12 Houweling AC, Gijezen LM, Jonker MA, et al. Renal cancer and pneumothorax risk in Birt-Hogg-Dubé syndrome; an analysis of 115 FLCN mutation carriers from 35 BHD families. Br J Cancer 2011; 105: 1912-1919.

13 Johannesma PC, Houweling AC, Reinhard R, et al. Early detection of hereditary renal cell cancer by improved evaluation of spontaneous pneumothorax patients. Ann Oncol 2014; 25: Suppl. 4, iv254.

\section{Inherent weaknesses of the current ICD coding system regarding idiopathic pulmonary fibrosis}

\section{To the Editor:}

Idiopathic pulmonary fibrosis (IPF) is the most prevalent of the idiopathic interstitial pneumonias (IIPs). It carries an ominous prognosis with a median survival of 3 years. Its epidemiology is poorly described because of its rarity and lack of unanimity in diagnostic and coding practices [1]. However, during the last few years, significant improvement has been achieved in our understanding of the pathogenesis, diagnosis 
and management of IPF and IIP in general. This is reflected in the 2011 American Thoracic Society (ATS)/European Respiratory Society (ERS)/Japanese Respiratory Society/ALAT consensus statement on IPF [2] and the 2013 ATS/ERS update of the International Multidisciplinary Classification of the Idiopathic Interstitial Pneumonias [3]. To obtain a robust understanding of the epidemiology of IPF is important, especially as novel therapies are emerging. The International Classification of Disease (ICD) coding system represents a great opportunity to create such registries that will expand our knowledge on IPF epidemiology. However, under its current formation, the 10th edition (ICD-10) coding system has severe deficiencies regarding the accurate classification of IPF.

The purpose of the ICD is to permit the systematic recording, analysis, interpretation and comparison of mortality and morbidity data collected in different countries or areas and at different times. However, it is acknowledged that although it is suitable for many different applications, it does not serve all the needs of its various users. It does not provide sufficient detail for some specialties and, sometimes, information on different attributes of health conditions [4]. IPF is such an example. In particular, ICD-10 classifies IPF under the term "other interstitial pulmonary diseases with fibrosis" ( J84.1). This category includes diffuse pulmonary fibrosis, fibrosing alveolitis (cryptogenic), Hamman-Rich syndrome, IPF and usual interstitial pneumonia (UIP) [4]. Given the current classification, some problems are readily evident, as follows.

1) In the most recent ATS/ERS update on the classification of IIPs, the term "cryptogenic fibrosing alveolitis" was removed, thus leaving IPF as the sole clinical term for this diagnosis [2]. The reason for this was to avoid ambiguity in the nomenclature and definition of the disease.

2) "Hamman-Rich syndrome" is an obsolete term that corresponds to acute interstitial pneumonia (AIP). AIP can complicate the natural course of IPF but it is a distinct clinical entity. It is frequently confused with other clinical entities characterised by rapidly progressive interstitial pneumonia, especially secondary acute interstitial pneumonia, acute exacerbations and accelerated forms of IPF. Furthermore, many authors use the above terms both erroneously and interchangeably [5].

3) UIP is a radiological and histological pattern. While UIP is the pathological background of IPF, it is not synonymous with it. Other clinical entities with a different prognosis can also be associated with UIP (e.g. chronic hypersensitivity pneumonitis, collagen vascular disease, pulmonary drug toxicity, asbestosis, familial IPF and Hermansky-Pudlak syndrome).

4) Finally, the term "diffuse pulmonary fibrosis" is a generic term that does not correspond to any specific clinical or histological entity. This carries the risk of becoming a "bucket" that will include cases of unspecified pulmonary fibrosis irrelevant to IPF. As interstitial lung diseases (ILDs) cover $>200$ different disease entities, this can lead to obvious misclassification. In our centre, $>50 \%$ of cases with a final diagnosis of IPF were initially referred as (unclassifiable) pulmonary fibrosis. Thus, based on our personal experience, ICD-10 can lead to false epidemiological data.

We suggest that the upcoming ICD should adopt the classification system proposed by the updated new IIPs classification of the ERS/ATS [3]. Specifically, we suggest the following.

1) Each one of the six major IIPs (IPF, idiopathic nonspecific interstitial pneumonia (NSIP), respiratory bronchiolitis-ILD, desquamative interstitial pneumonia, cryptogenic organising pneumonia and AIP) should receive a specific code.

2) A separate code should be designated for unclassifiable pulmonary fibrosis. However, this diagnosis should not be considered an easy solution. We recommend that a diagnosis of unclassifiable pulmonary fibrosis should be restricted to expert centres where the diagnostic approach within the context of multidisciplinary discussion according to current guidelines is feasible $[2,6]$.

3) Regarding rare clinical entities (acute fibrinous and organising pneumonia, and idiopathic pleuroparenchymal fibroelastosis), given their rarity, we do not think that each one should be classified under a separate code but under the term "other rare specified interstitial pulmonary diseases". We suggest that lymphocytic interstitial pneumonia should be categorised in the context of lymphoproliferative disorders (the justification for this is beyond the scope of this correspondence).

4) It is not yet clear whether combined pulmonary fibrosis emphysema represents a distinct clinical phenotype with a different prognosis. So far, studies have reached different conclusions regarding mortality $[7,8]$. Therefore, we recommend that it should not be classified as a distinct clinical entity but according to the fibrotic disease with which it is observed (e.g. UIP, NSIP or collagen tissue-related ILD).

Currently, after years of negative clinical trials and disappointment, there is effective medication for IPF patients [9-12]. Besides pharmaceutical management, genetic studies and preventive and regenerative strategies (including stem cell transplantation research [13]) exhibit hopeful results. In order to evaluate the impact of the new therapeutic approaches, it is important to have valid data regarding the incidence, 
prevalence and mortality of IPF at both local and international levels. An updated ICD based on the current ATS/ERS classification of the IIPs can be a vital tool for achieving this goal.

\section{@ERSpublications \\ ICD-10 does not adequately classify IPF http://ow.ly/HHNqD}

Vasilios Tzilas and Demosthenes Bouros

Dept of Pneumonology, Medical School, Democritus University of Thrace, Alexandroupolis, Greece.

Correspondence: Vasilios Tzilas, Dept of Pneumonology, Medical School, Democritus University of Thrace, 68100 Alexandroupolis, Greece. E-mail: tzilasvasilios@gmail.com

Received: Nov 062014 | Accepted: Dec 162014

Conflict of interest: None declared.

\section{References}

1 Ley B, Collard HR. Epidemiology of idiopathic pulmonary fibrosis. Clin Epidemiol 2013; 5: 483-492.

2 Raghu G, Collard HR, Egan JJ, et al. An official ATS/ERS/JRS/ALAT statement: idiopathic pulmonary fibrosis: evidence-based guidelines for diagnosis and management. Am J Respir Crit Care Med 2011; 183: 788-824.

3 Travis WD, Costabel U, Hansell DM, et al. An Official American Thoracic Society/European Respiratory Society statement: update of the International Multidisciplinary Classification of the Idiopathic Interstitial Pneumonias. Am J Respir Crit Care Med 2013; 188: 733-748.

4 World Health Organization. International Statistical Classification of Diseases and Related Health Problems. 10th Revision. Geneva, WHO, 2010.

5 Bouros D, Nicholson AC, Polychronopoulos V, et al. Acute interstitial pneumonia. Eur Respir J 2000; 15: 412-418.

6 Flaherty KR, Andrei A, King TE Jr, et al. Idiopathic interstitial pneumonia: do community and academic physicians agree on diagnosis? Am J Respir Crit Care Med 2007; 175: 1054-1060.

7 Ryerson CJ, Hartman T, Elicker BM, et al. Clinical features and outcomes in combined pulmonary fibrosis and emphysema in idiopathic pulmonary fibrosis. Chest 2013; 144: 234-240.

8 Mejia M, Carrillo G, Rojas-Serrano J, et al. Idiopathic pulmonary fibrosis and emphysema: decreased survival associated with severe pulmonary arterial hypertension. Chest $2009 ; 136: 10-15$.

9 Noble PW, Albera C, Bradford WZ, et al. Pirfenidone in patients with idiopathic pulmonary fibrosis (CAPACITY): two randomized trials. Lancet 2011; 377: 1760-1769.

10 Bouros D. Pirfenidone for idiopathic pulmonary fibrosis. Lancet 2011; 377: 1727-1729.

11 King TE Jr, Bradford WZ, Castro-Bernardini S, et al. A phase 3 trial of pirfenidone in patients with idiopathic pulmonary fibrosis. N Engl J Med 2014; 370: 2083-2092.

12 Richeldi L, du Bois RM, Raghu G, et al. Efficacy and safety of nintedanib in idiopathic pulmonary fibrosis. $N$ Engl J Med 2014; 370: 2071-2082.

13 Tzouvelekis A, Paspaliaris V, Koliakos G, et al. A prospective, non-randomized, no placebo-controlled, phase Ib clinical trial to study the safety of the adipose derived stromal cells-stromal vascular fraction in idiopathic pulmonary fibrosis. J Transl Med 2013; 11: 171. 